\title{
Comparative Study of the Rate of Tooth Movement Between Corticotomy and Piezocision to Facilitate En-Masse Retraction in Bimaxillary Protrusion.
}

\author{
Rehab A Khalil", Waleed M Abbas ${ }^{\star *}$, Waleed El-Sayed Refaat ${ }^{\star \star \star}$, Ahmed A Ramadan $^{\star \star \star}$
}

\section{ABSTRACT:}

Objective: The aim of this study was to evaluate the rate of orthodontic tooth movement and the time needed for extraction space closure when corticotomy and piezocision were used to facilitate en-masse retraction in bimaxillary protrusion cases. Subjects and Methods: The sample of this study consisted of twenty subjects having Class I malocclusion with bimaxillary protrusion and requiring extraction of four first premolars and en-masse retraction of the anterior segments on 6oth arches. The sample was randomly divided into two equal groups; group I:corticotomy was performed by using piezosurgery through flap reflection and group II: corticotomy was performed by using piezocision (flapless corticotomy). Study models were obtained just before surgery and in every month for 6 months after surgery to measure the rate of orthodontic tooth movement in 6oth groups. After completing the en-masse retraction, the retraction time in months was recorded for the right and left sides and averaged. Results: Group I showed a statistically significant shorter retraction time than group II. Group I showed a statistically significant increase in the rate of tooth movement from the $2^{\text {nd }}$ to the $5^{\text {th }}$ month in the upper arch. For the lower arch, group I exhibited a significant increase in the rate of tooth movement in the $4^{\text {th }}$ month. Conclusion: Corticotomy involving flap reflection showed a shorter retraction time and higher rates of tooth movement than piezocision during en-masse retraction.

\section{INTRODUCTION}

Reducing treatment time is a primary concern for all patients receiving orthodontic treatment. Corticotomy is a surgical technique that involves cutting or perforating the cortical bone with minimal penetration into the bone marrow. The first corticotomy technique described by Kole ${ }^{(1)}$ was depending on creating bony blocks through buccal and lingual vertical interproximal cuts that were connected by a horizontal osteotomy cut. In contrast to this theory, Wilcko et al., ${ }^{(2,3)}$ evaluated accelerated osteogenic orthodontics and reported that tooth movement occurred by a demineralization/remineralization process that strongly correlated to the RAP (Regional Acceleratory Phenomena) as described by Frost. $^{(4,5)}$ A shorter treatment time was documented in a case report after performing corticotomy on the buccal and lingual sides. ${ }^{(6)}$ Rapid tooth movement was achieved with a more conservative approach ${ }^{(7,8)}$ in which the

\footnotetext{
* Assistant Lecturer, Department of Orthodontics, Faculty of Dentistry, Beni-Suef University.

** Lecturer of Oral Medicine and periodontology, Faculty of Dentistry, Ain Shams University.

*** Professor of Orthodontics, Faculty of Dentistry, Suez Canal University.
} 
mucoperiosteal flap was reflected on the labial side only.

Corticotomy assisted en-masse retraction was evaluated in previous studies. ${ }^{(9-12)}$ It was found that the rate of retraction was accelerated in the first two months after corticotomy. ${ }^{(9,11)}$ A significant reduction in retraction time after first premolar extraction was reported when a corticotomy group was compared to a control one. ${ }^{(10)}$ Another study advocated the use of single side corticotomy as no significant difference in retraction time was found when buccal and palatal corticotomy were compared. ${ }^{(12)}$

In an attempt to decrease surgical invasion, piezocision was introduced as a minimally invasive surgical technique that used a piezosurgery knife to produce cortical alveolar incisions through microincisions in the periosteum. Piezocision was suggested for rapid correction of patients with Class II malocclusion. ${ }^{(13,14)}$ A review of the technique suggested using the piezocision in a generalized, localized, or sequential manner and claimed that the technique could extend the RAP to 6 months. ${ }^{(15)}$ Rapid canine retraction was achieved in another study when corticotomy and piezocision were evaluated. ${ }^{(16)}$ In contrast to previous findings, it was found that piezocision was ineffective in accelerating tooth movement. ${ }^{(17)}$ A significant increase in the rate of canine retraction was recorded in a recent study when piezocision and laser-assisted flapless corticotomy were investigated. ${ }^{(18)}$

Bimaxillary protrusion is a common orthodontic problem characterized by proclination of maxillary and mandibular incisors, facial convexity and incompetent lips. Treatment of bimaxillary protrusion involved surgical treatment through anterior segmental osteotomy or by orthodontic correction through extraction of four first premolars and retraction of anterior teeth with maximum anchorage. ${ }^{(19)}$
This treatment modality may not be the preferred technique as excessive retraction of anterior teeth might lead to complications such as root resorption and alveolar bone loss. Previous studies ${ }^{(19,20)}$ recommended retraction of anterior teeth combined with alveolar corticotomy to minimize the potential risks associated with retraction of anterior teeth.

Reviewing the literature, there was no previous data comparing the effect of corticotomy and piezocision on en-masse retraction during the treatment of bimaxillary protrusion. Besides, no data was found in the available literature regarding the use of piezocision in facilitating en-masse retraction in the lower arch as several reports ${ }^{(13,14,21)}$ used the technique in non-extraction cases. Therefore, the aim of this study was to evaluate the rate of orthodontic tooth movement and the time needed for extraction space closure when corticotomy and piezocision were used to facilitate en-masse retraction in bimaxillary protrusion cases.

\section{SUBJECTS AND METHODS}

\section{Sample:}

This study was carried out on twenty subjects (19 females, 1 male) selected from the out patients of Orthodontic clinic, Faculty of Dentistry, Suez Canal University.The inclusion criteria included Class I malocclusion with bimaxillary protrusion requiring extraction of four first premolars and en-masse retraction of the anterior segments. The age was ranged from $15-25$ years. The oral hygiene was fair and no systemic diseases were reported.

The sample was randomly divided into two equal groups:

Group I: corticotomy was performed by using piezosurgery through flap reflection on both arches.

Group II: corticotomy was performed by using piezocision on both arches. 
Simple randomization was designed with the aid of computer generated schedule in Excel with 1:1 allocation ratio followed by allocation concealment. Blinding of the operators was not applicable and so blinding was only limited to the outcome assessment. All subjects and parents were informed of the surgical procedures and signed a consent form.

\section{Method:}

The following records were obtained before and after treatment: extraoral and intraoral photographs, orthodontic study models, panoramic radiograph and lateral cephalometric radiograph. Fixed appliance was inserted (0.022 inch metal bracket*). Leveling and alignment phase was proceeded until reaching 0.017 x 0.025 ', stainless steel wire.

The followings were attained before surgery:

1- Orthodontic study model.

2- Vector TAS** miniscrews (diameter1.4 mm and $8 \mathrm{~mm}$ in length) were inserted between the first molars and second premolars.

3- Crimpable hooks*** of $10 \mathrm{~mm}$ length were attached to the archwires between the lateral incisors and canines.

\section{Surgical procedures:}

The surgical procedures were performed under the use of local anaesthesia. The four first premolars were extracted just before surgery.

Group I: corticotomy was performed by using piezosurgery through flap reflection

A submarginal scalloped flap design was performed. A full-thickness mucoperiosteal flap was reflected by the use of mucoperiosteal elevator beyond the apices of the upper and lower six anterior teeth. A piezosurgery knife**** was used to create interproximal (Figure 1) vertical grooves (3 $\mathrm{mm}$ in depth verified by the millimetric signs of the piezosurgery knife). The flap was repositioned and sutured with 4-0 absorbable sutures with the interrupted technique.

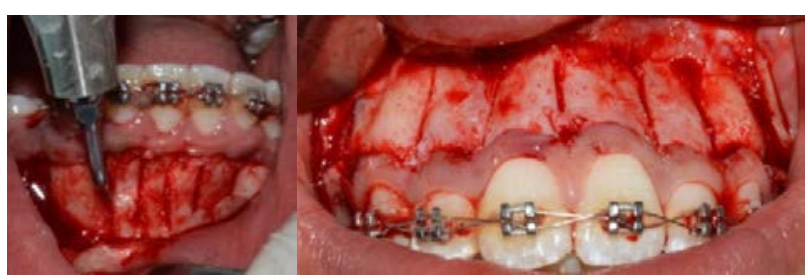

Figure (1): Vertical corticotomy grooves after flap reflection.

Group II: corticotomy was performed by using piezocision (flapless corticotomy)

Vertical interproximal incisions were cut $4 \mathrm{~mm}$ apical to the interdental papillae to 2-3 $\mathrm{mm}$ apical to the mucogingival junction in the upper and lower six anterior teeth. Cortical alveolar interproximal incisions (3mm in depth) were made with the same piezosurgery knife through the gingival incisions (Figure 2). The incisions were sutured with the same 4-0 absorbable sutures with the interrupted technique.

En-masse retraction was started immediately after surgery on 0.017 x 0.025 "' stainless steel wires in both arches by the use of $9 \mathrm{~mm}$ $\mathrm{NiTi}^{* * * * *}$ closed coil springs ${ }^{(22)}$ that were inserted from the miniscrews to the crimpable hooks.

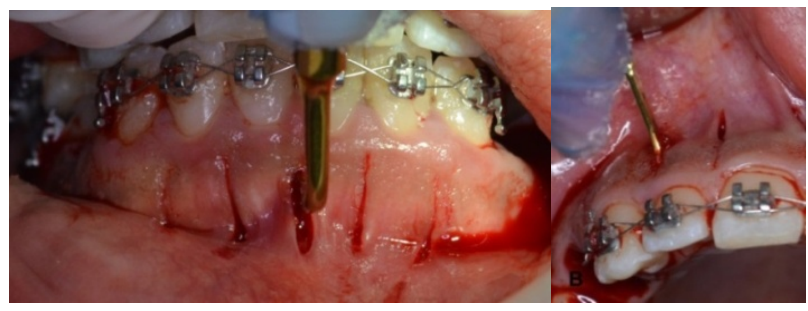

Figure (2): Piezosurgery Knife performing vertical corticotomy grooves in piezocision group.

* Gemini MBT metal bracket, 3M Unitek Orthodontic Products, Monrovia, CA.

**Ormco, Glendora, CA.

***Hubit, Gyeonggi-do, Korea.

****Variosurg, NSK, Tokyo, Japan.

******Modern Orthodontics, Ludhiana, India. 
Impressions were taken every month for 6 months after surgery and study casts were used to measure the rate of orthodontic tooth movement in both groups. The casts were scanned by Xerox scanner and the images were uploaded into Image J software.The distances in the upper arch were measured according to Ziegler and Ingervall ${ }^{(23)}$ while in the lower arch, the distances between the distal surface of the canines and the mesial surface of the second premolars were recorded.

After completing the en-masse retraction, the retraction time in months was recorded for the right and left sides and averaged.

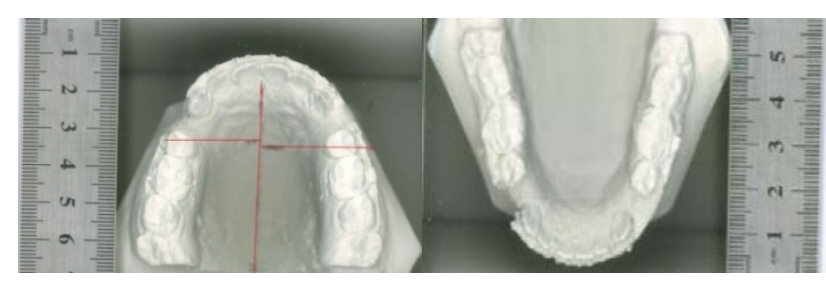

Figure (3): Scanned casts.

\section{RESULTS}

\section{I) Time needed for extraction space closure:}

Student's t-test was used to compare the space closure time between the two groups (Table 1). Group I showed a statistically significant decrease in the time needed for extraction space closure than group II for both the upper and lower arches.

\section{II-Rate of tooth movement:}

Student's t-test was used to compare the rate of tooth movement between the two groups in each month for 6 months (Table (2) for the upper arch and Table (3) for the lower arch).For the upper arch, there was no significant difference in the rate of tooth movement between the two groups in the $1^{\text {st }}$ and $6^{\text {th }}$ months. Group I showed a statistically significant increase in the rate of tooth movement from the $2^{\text {nd }}$ to the $5^{\text {th }}$ month.For the lower arch, there was no significant difference in the rate of tooth movement between the two groups except in the $4^{\text {th }}$ month in which group I exhibited a significant increase.

Table (1): Mean, standard deviation (SD) and results of the Student's t-test of space closure time in months for the two groups.

\begin{tabular}{|l|c|c|c|c|c|c|}
\hline \multicolumn{2}{|c|}{} & \multicolumn{2}{c|}{ Group I (Flap) } & \multicolumn{2}{c|}{ Group II (Flapless) } & \multirow{2}{*}{ p-value } \\
\cline { 3 - 7 } & Mean & SD & Mean & SD & \\
\hline $\begin{array}{l}\text { Total time for extraction } \\
\text { space closure (in months) }\end{array}$ & Upper & 7.80 & 0.96 & 9.98 & 1.35 & $0.001^{*}$ \\
\cline { 2 - 8 } & Lower & 7.52 & 0.91 & 9.89 & 1.26 & $\leq 0.001 *$ \\
\hline
\end{tabular}

$*=$ Significant, NS=Non-significant.

Table (2): Mean, standard deviation (SD) and results of the Student's t-test of the monthly rate of tooth movement (in $\mathrm{mm}$ ) of the upper arch for the two groups.

\begin{tabular}{|c|c|c|c|c|c|c|}
\hline \multicolumn{2}{|c|}{} & \multicolumn{2}{c|}{ Group I (Flap) } & \multicolumn{2}{c|}{ Group II (Flapless) } & \multirow{2}{*}{ p-value } \\
\cline { 3 - 7 } & Mean & SD & Mean & SD & \\
\hline \multirow{3}{*}{$\begin{array}{c}\text { Upper arch } \\
\text { (In mm) }\end{array}$} & 1st month & 1.38 & 0.31 & 1.26 & 0.19 & 0.314 NS \\
\cline { 2 - 7 } & 2nd month & 1.35 & 0.24 & 1.15 & 0.17 & $0.049^{*}$ \\
\cline { 2 - 7 } & 3rd month & 1.15 & 0.25 & 0.95 & 0.11 & $0.031^{*}$ \\
\cline { 2 - 7 } & 4th month & 0.91 & 0.12 & 0.79 & 0.07 & $0.015^{*}$ \\
\cline { 2 - 7 } & 5th month & 0.80 & 0.05 & 0.72 & 0.07 & $0.013^{*}$ \\
\cline { 2 - 7 } & 6th month & 0.71 & 0.07 & 0.66 & 0.08 & $0.227 \mathrm{NS}$ \\
\hline
\end{tabular}

*= Significant, NS=Non-significant. 
Table (3): Mean, standard deviation (SD) and results of the Student's t-test of the monthly rate of tooth movement (in mm) of the lower arch for the two groups.

\begin{tabular}{|c|c|c|c|c|c|c|}
\hline \multicolumn{2}{|c|}{} & \multicolumn{2}{|c|}{ Group I (Flap) } & \multicolumn{2}{c|}{ Group II (Flapless) } & \multirow{2}{*}{ p-value } \\
\cline { 3 - 6 } & Mean & SD & Mean & SD & \\
\hline \multirow{3}{*}{$\begin{array}{c}\text { Lower arch } \\
\text { (In mm) }\end{array}$} & 1st month & 1.25 & 0.17 & 1.20 & 0.31 & 0.669 NS \\
\cline { 2 - 6 } & 2nd month & 1.23 & 0.17 & 1.11 & 0.23 & 0.225 NS \\
\cline { 2 - 6 } & 3rd month & 1.01 & 0.15 & 0.93 & 0.10 & 0.188 NS \\
\cline { 2 - 7 } & 4th month & 0.91 & 0.11 & 0.77 & 0.05 & $0.002^{*}$ \\
\cline { 2 - 7 } & 5th month & 0.77 & 0.11 & 0.71 & 0.08 & 0.194 NS \\
\cline { 2 - 6 } & 6th month & 0.70 & 0.08 & 0.65 & 0.09 & 0.168 NS \\
\hline
\end{tabular}

*= Significant, NS=Non-significant.

\section{DISCUSSION}

Acceleration of tooth movement has been the focus of many orthodontic clinicians. The present study was carried out on twenty subjects (19 females, 1 male) having Class I bimaxillary protrusion. The age of the subjects included in the study ranged from 15-25 years which was consistent with former studies. ${ }^{(10,16)}$ Piezosurgery was used to perform corticotomy cuts because it enables micrometric cutting with no bone loss so reduces postoperative pain and traumatic stress. ${ }^{(15)}$ The rate of tooth movement was measured for the period of 6 months in accordance with the finding of Frost ${ }^{(5)}$.

For group I, the results of the current study showed that the time needed for extraction space closure was in agreement with El Gemeay et al., ${ }^{(2)}$ and Wilcko et al., ${ }^{(24)}$ for the upper arch. The results of the lower arch in this study matched those of Lino et al., ${ }^{(6)}$ who declared that en-masse retraction of the lower arch could be achieved in 7 months while Khatri el al., ${ }^{(11)}$ reported space closure time of 6 months after corticotomy which could be attributed to the difference in anchorage preservation method. The results of the present study differed from other studies ${ }^{(9,10)}$ which reported shorter time for space closure .This might be interpreted on the basis of variation in methodology and anchorage preparation.

For group II (flapless technique), the results of the current study for retraction time was consistent with Tuncer et al., ${ }^{(17)}$ for the upper arch. For the lower arch, no data was found in the available literature concerning the evaluation of piezocision for en-masse retraction of the lower anterior segment.

The results demonstrated that group I showed a statistically significant decrease in time needed for extraction space closure than group II for the upper and lower arches. This observation was in agreement with other studies ${ }^{(16,17)}$ which reported reduced RAP effect when a flap was not reflected.

Regarding the rate of tooth movement in the upper arch, the results were consistent with the nature of the RAP as described by Frost ${ }^{(5)}$ so the peak of the RAP in the flapless group might be reached in the first month and that could explain the non-significant difference between the two groups. In the $6^{\text {th }}$ month, no significant difference in the rate was noticed and it is suggested to be due to the subsidence 
of the RAP. The rates from the $2^{\text {nd }}$ to the $5^{\text {th }}$ month were significantly higher in group I and this could be due to the extensive injury of the flap that might trigger a stronger RAP response.

For the lower arch, the only statistically significant difference in the rate was reported in the $4^{\text {th }}$ month in which group I exhibited a significant increase and believed to be due to more declination of the RAP effect in group II than in group I. The current finding could be attributed to high bone density in the mandible. ${ }^{(21)}$ This finding is in agreement with a previous study ${ }^{(8)}$ which described that the RAP response was transient and could last to 34 months. The increased time of space closure of group II other than the significant decrease of the rate in the $4^{\text {th }}$ month, is suggested to be due to slower rates after the $6^{\text {th }}$ month.

\section{CONCLUSION}

1- Group I showed a statistically significant shorter retraction time than group II.

2- Regarding the rate of tooth movement in the upper arch, group I showed a statistically significant increase in the rate of tooth movement from the $2^{\text {nd }}$ to the $5^{\text {th }}$ month. For the lower arch, group I exhibited a significant increase in the rate of tooth movement in the $4^{\text {th }}$ month.

3- For both groups, the rate of tooth movement was decreased as time passed.

\section{REFERENCES}

1. Kole H. Surgical operations on the alveolar ridge to correct occlusal abnormalities. Oral Surg Oral Med Oral Pathol .1959; 12: 277-88.

2. Wilcko WM, Wilcko T, Bouquot JE, Ferguson DJ. Rapid orthodontics with alveolar reshaping: two case reports of decrowding. Int $\mathrm{J}$ Periodontics Restorative Dent. 2001; 21: 9-19.
3. Wilcko MT, Wilko WM, Bissada NF. An evidence-based analysis of periodontally accelerated orthodontic and osteogenic techniques: a synthesis of scientific perspective. Semin Orthod. 2008; 14: 305-16.

4. Frost HM. The regional accelerated phenomenon. Orthop Clin N Am. 1981;12:725-6.

5. Frost MH. The biology of fracture healing: an overview for clinicians,part I. Clin Orthod. 1989;248:283-93.

6. Lino S, Sakoda S, Miyawaki S. An adult bimaxillary protrusion treated with corticotomy-facilitated orthodontics and titanium miniplate. Angle Orthod. 2006; 76:1074-82.

7. Germeç D, Giray B, Kocadereli I, Enacar A. Lower incisor retraction with a modified corticotomy. Angle Orthod. 2006; 76: 882-90.

8. Aboul-Ela SM, El-Beialy AR, El-Sayed KM, Selim EM, El-Mangoury NH, Mostafa YA. Miniscrew implant-supported maxillary canine retraction with and without corticotomy-facilitated orthodontics. Am J Orthod Dentofacial Orthop. 2011; 139: 252-9.

9. Sakthi SV, Vikraman B, Shobana VR, Iyer SK, Krishnaswamy NR. Corticotomy-assisted retraction: An outcome assessment. Indian J Dent Res. 2014; 25:748-54.

10. Bhattacharya $\mathrm{P}$, Bhattacharya $\mathrm{H}$, Anjum A, Bhandari R, Agarwal DK, Gupta A, Ansar J. Assessment of corticotomy facilitated tooth movement and changes in alveolar bone thickness - A Ct scan study. J Clin Diagn Res.2014; 8: ZC26-30.

11. Khatri JM, Mantri PJ, Mehta VP. Corticotomy-race of orthodontic treatment with the time. Int J Dent Health Sci. 2015; 2:143-52.

12. El Gemeay WE, Nadim MA, Hamed TAB, Bedair TM, El-Kadi AA. Comparison of labial corticotomy vs palatal corticotomy during en masse retraction with miniscrews as anchorage units. Egyptian Orthodontic Journal. 2015; 47:93-103. 
13. Dibart S, Sebaoun JD, Surmenian J. Piezocision: a minimally invasive, periodontally accelerated orthodontic tooth movement procedure. Compend Contin Educ Dent. 2009; 30: 342-50.

14. Dibart S, Surmenian J, Sebaoun JD, Montesani L. Rapid treatment of Class II malocclusion with piezocision: two case reports. Int J Periodontics Restorative Dent. 2010; 30:487-93.

15. Dibart S, Keser E, Nelson D. Piezocisionassisted orthodontics: Past, present, and Future. Semin Orthod.2015;21:170-5.

16. Abbas NH, Sabet NE, Hassan IT. Evaluation of corticotomy-facilitated orthodontics and piezocision in rapid canine retraction. Am J Orthod Dentofacial Orthop. 2016;149:473-80.

17. Tunçer NI, Arman-Özçırpıcı A, Oduncuoğlu BF, Göçmen JS, Kantarcı A. Efficiency of piezosurgery technique in miniscrew supported en-masse retraction: a single-centre, randomized controlled trial. Eur J Orthod. 2017;39:586-94.

18. Alfawal AMH, Hajeer MY, Ajaj MA, Hamadah O, Brad B.Evaluation of piezocision and laser-assisted flapless corticotomy in the acceleration of canine retraction: a randomized controlled trial. Head \& Face Medicine. 2018;14:4.
19. Lee JK, Chung KR, Baek SH. Treatment outcomes of orthodontic treatment, corticotomy-assisted orthodontic treatment, and anterior segmental osteotomy for bimaxillary dentoalveolar protrusion. Plast Reconstr Surg. 2007; 120:1027-36.

20. Nahm KY, Kang JH, Moon SC, Choi YS, Kook YA, Kim SH, Huang JC.Alveolar bone loss around incisors in Class 1 bidentoalveolar protrusion patients: a retrospective threedimensional cone beam CT study. Dentomaxillofac Radiol. 2012;41:481-8.

21. Charavet C, Lecloux G, Bruwier A, Rompen E, Maes N, Limme M, Lambert F.Localized piezoelectric alveolar decortication for orthodontic treatment in adults: A randomized controlled trial. J Dent Res. 2016; 95: 1003-9.

22. Dixon V, Read MJF, O’Brien KD, Worthington HV, Mandall NA. A randomized clinical trial to compare three methods of orthodontic space closure. J Orthod. 2002;29:31-6.

23. Ziegler P, Ingervall B. A clinical study of maxillary canine retraction with a retraction spring and with sliding mechanics. Am J Orthod Dentofacial Orthop. 1989;95:99-106.

24. Wilcko W, Wilcko MT. Accelerating tooth movement: The case for corticotomy-induced orthodontics.Am J Orthod Dentofacial Orthop. 2013;144:4-13. 